\title{
Carcinoid tumours of the bronchus: a 33 year experience
}

\author{
RAYMOND HURT, MICHAEL BATES \\ From the Regional Thoracic Surgical Centre, North Middlesex Hospital, London
}

\begin{abstract}
The term adenoma of the bronchus is discussed, and 79 cases of bronchial carcinoid seen from 1951 to 1983 are reviewed. The symptoms, radiological findings, and bronchoscopic appearances are described. There was no case of the carcinoid syndrome. In no case did haemorrhage cause any serious problem after biopsy at rigid bronchoscopy. In three patients the tumour was reported to be an oat cell carcinoma-in two on the basis of material obtained at fibreoptic bronchoscopy. Resection was by pneumonectomy in 10 cases, lobectomy in 52, segmentectomy in six, a bronchoplastic procedure without resection of lung in seven cases, enucleation in two, and a wedge resection in one case. There was one case of atypical carcinoid which was found at operation to be unresectable. A 5-30 year follow up in 57 cases revealed a recurrence of tumour in two cases, nine and 16 years after lung resection. No recurrence occurred in the nine cases treated by conservative bronchial resection with conservation of lung tissue. An actuarially assessed life table analysis shows survival rates of $94 \%$ after 10 years, $80 \%$ after 15 years, and $64 \%$ after 25 years without recurrence. The similarity of carcinoid to oat cell carcinoma is noted and the serious clinical implications of this are analysed, especially in view of the increasing use of fibreoptic bronchoscopy. The malignant potential of carcinoid and the extent of pulmonary resection is discussed. It is concluded that a carcinoid tumour of the lung has only slight malignant potential and that it may be treated by bronchotomy or sleeve resection of the bronchus in suitable cases. If serious infective changes have occurred in the lung distal to the tumour or if the tumour has extended into the lung parenchyma ( $88 \%$ of cases in this series) lung resection will be necessary. The follow up period should be for at least 25 years, in view of the incidence of late recurrence.
\end{abstract}

Carcinoid tumours of the bronchus are the commonest benign bronchial tumour and comprise about $4 \%$ of all lung tumours, although this incidence is diminishing owing to the increasing incidence of carcinoma of the bronchus.' The series reported here is the largest so far reported from the United Kingdom-larger series have been reported only from the Mayo Clinic, Rochester, Minnesota (203 patients) ${ }^{2}$ and in a review from Sweden of the papers published worldwide with special reference to choice of operation (313 patients). ${ }^{3}$ The clinical presentation and pathological appearances have now been well established. ${ }^{4-31}$ The term adenoma of the bronchus is meaningless and should no longer be

Address for reprint requests: Mr RL Hurt, North Middlesex Hospital, London N18 1QX.

Accepted 7 March 1984 used, even though it appeared as the title of a leading article as recently as $1981 . .^{32}$ By definition an adenoma is a benign tumour: yet carcinoid, adenoid cystic carcinoma, mucoepidermoid tumour, and mucus gland cyst adenoma have all been included under this heading. These neoplasms differ widely in their malignant potential, and as a result the published reports of the last 20 years are often misleading and confused.

\section{Patients and methods}

From 1951 to 198379 patients with carcinoid tumour of the bronchus were seen (table 1). There were 38 men and 41 women, and the mean age was 47 years. Six patients were under the age of 19 years, the youngest two both being 14 years of age. Two patients were over 70 , aged 71 and 75 years. 
Table 1 Sex and age distribution of 79 cases of bronchial carcinoid, 1951-83

\begin{tabular}{lcc}
\hline & Age $(y)$ & No of cases \\
\hline & $10-19$ & 6 \\
$20-29$ & 6 \\
$30-39$ & 11 \\
& $40-49$ & 24 \\
& $50-59$ & 17 \\
Male & $60-69$ & 13 \\
Female & $70-80$ & 2 \\
& & 38 \\
\hline
\end{tabular}

Table 2 Symptoms in 79 cases of bronchial carcinoid

\begin{tabular}{lc}
\hline & No $(\%)$ of cases \\
\hline Recurrent infection & $39(49)$ \\
Haemoptysis & $25(32)$ \\
Pain & $4(5)$ \\
Persistent cough & $4(5)$ \\
Wheeze & $2(3)$ \\
Dyspnoea & $3(4)$ \\
No symptoms & $13(17)$ \\
\hline
\end{tabular}

All the tumours, except for one atypical carcinoid, were resected. A 5-30 year follow up has been achieved in 57 cases.

\section{Results}

\section{SYMPTOMS}

The presenting symptoms (table 2 ) were similar to those recorded in previous series. In half the cases there was persisting or recurrent lung infection and in one third of the cases haemoptysis. The remainder presented with pain, persistent cough, wheeze, or dyspnoea. One fifth of patients denied having any symptoms and presented after routine chest radiography. Many of the patients had a long history and had gross bronchiectasis or infection in the lung distal to the tumour. The duration of symptoms in patients with haemoptysis was much shorter. None of the patients presented with the carcinoid syndrome of diarrhoea and flushing of the face associated with increased serotonin secretion in the blood or 5-hydroxyindole acetic acid in the urine.

\section{RADIOLOGICAL FINDINGS}

All patients had an abnormal chest radiograph though in the two cases presenting with a wheeze the radiograph might easily have been passed as normal. In 57 cases there was a segmental or lobar area of collapse and consolidation in the lung; in 20 cases a well defined opacity, usually near the hilum; and in two cases emphysema of part of a lung, which at bronchoscopy was seen to be obstructive in type.
BRONCHOSCOPIC APPEARANCES

The tumour was not visible on rigid bronchoscopy in 17 cases but in the remaining 62 the tumour was seen and biopsy specimens were taken in all cases but one. Appreciable haemorrhage after biopsy occurred in only two cases and was easily controlled.

In three cases the tumour was reported as an oat cell carcinoma-one 20 years ago before the present refinements of histological diagnosis and two more recently on the basis of the small biopsy specimen obtained at fibreoptic bronchoscopy. In these last two cases the innocent nature of the tumour was appreciated only later, at rigid bronchoscopy in one and at pneumonectomy in the other.

The tumours were situated almost entirely in the larger named bronchi (table 3). None occurred in the trachea. In nine cases it was in a main bronchus, in 13 cases in the right intermediate bronchus, and in 55 cases in an upper, middle, or lower lobe bronchus, often at its origin. In two cases the tumour was situated in the periphery of the lung. The tumour was in the right lung in 40 cases and the left in 39.

\section{SURGICAL PROCEDURES}

The treatment of these tumours (table 4) has been essentially conservative resection in the belief that they are not frankly malignant. This question of malignancy will be discussed later. The type of oper-

Table 3 Site of bronchial carcinoid tumour in the 79 cases

\begin{tabular}{lc}
\hline & No of cases \\
\hline Trachea & 0 \\
Main bronchus & 9 \\
Lobar bronchus & \\
$\quad$ upper & 19 \\
intermediate & 13 \\
middle & 10 \\
lower & 26 \\
Lung parenchyma & 2 \\
Left side & 39 \\
Right side & 40 \\
\hline
\end{tabular}

Table 4 Operative procedures in the 79 cases

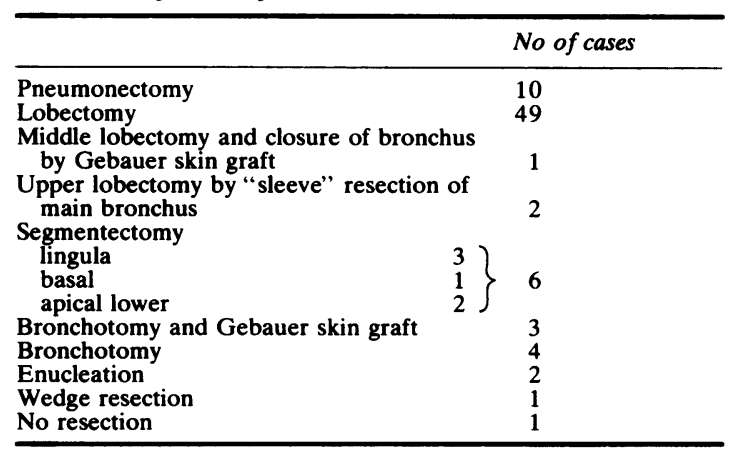


ation has depended on the site of the tumour and the condition of the lung distal to the blockage.

Ten cases were treated by pneumonectomy, 49 by straightforward lobectomy, and six by segmentectomy. Three cases were treated by bronchotomy and a Gebauer skin graft to close the bronchial defect and one case by a middle lobectomy and a skin graft (fig 1). Two cases were treated by upper lobectomy by sleeve resection of the main bronchus, four by bronchotomy alone (fig 2), two by enucleation from the periphery of the right lower lobe, and one case by wedge resection.

The one patient with atypical carcinoid was a 41 year old man with a right hilar shadow. At thoracotomy the tumour could not be removed because his oesophagus was severely affected by tumour and he had unsuspected metastases in the liver.

The oldest patient in the series was a 75 year old woman who had a tumour in the left main bronchus, causing complete collapse of the lung. She was otherwise fit and was of lean build and she had an excellent outcome, with a new lease of life after pneumonectomy.

\section{MORTALITY AND MORBIDITY}

The only hospital death in the series was in a 46 year old Spaniard who developed a carcinoid in the left main bronchus 20 years after a left thoracoplasty for extensive pulmonary tuberculosis. He died from
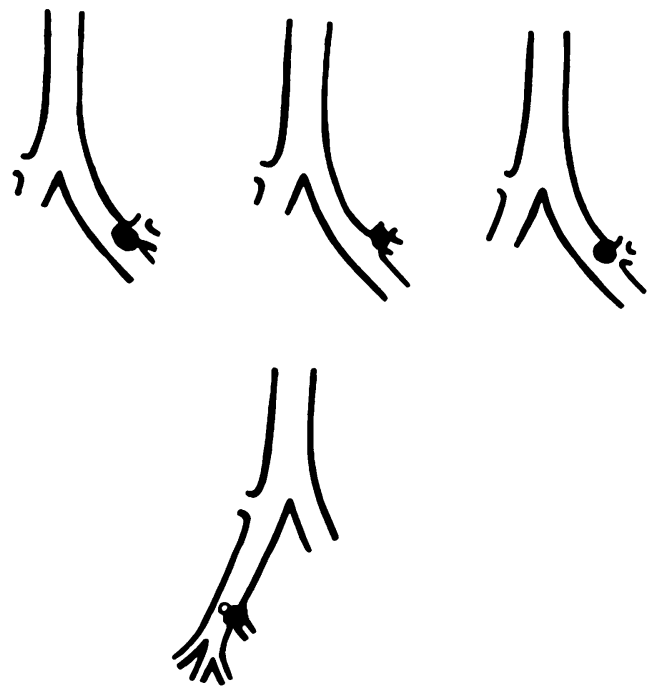

Fig 1 Site of tumour in the four cases treated by Gebauer skin graft; in the upper three cases no lung resection was necessary and in the lower case a middle lobectomy was required.
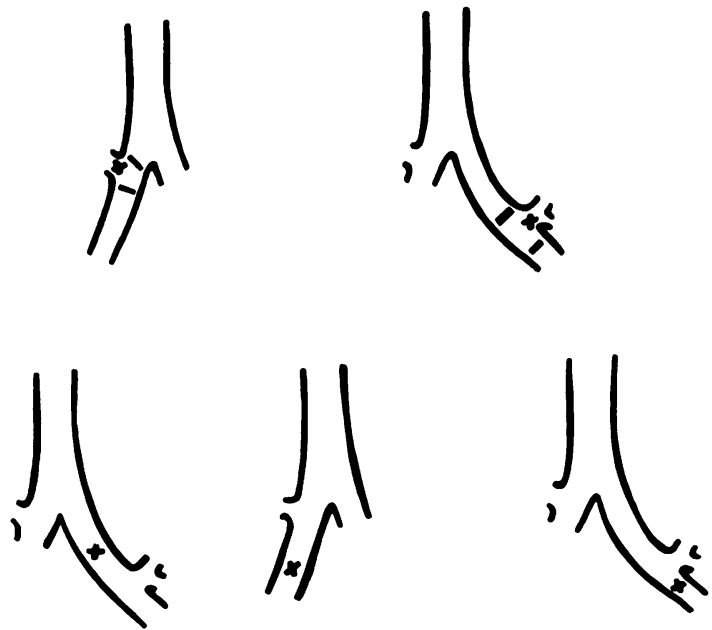

Fig 2 Site of tumour in the two cases treated by upper lobectomy with sleeve resection (above) and the four cases treated by bronchotomy alone (below); the middle diagram shows the site in two cases.

operative haemorrhage at the time of pneumonectomy. All the other patients recovered uneventfully and there were no late operative complications.

\section{HISTOLOGY}

In six of the 79 cases ossification was seen in part of the tumour on histological examination. It had not been seen on the routine radiographs.

Many cases were found at operation to have lymph node enlargement, but this was due to infection in the lung distal to the tumour except in one case, in which the gland was invaded by tumour. This patient was treated in 1951 and has unfortunately been lost to follow up.

Tumour cells were present in the capillaries and lymphatics in the case of atypical carcinoid and in addition the cells showed a low mitotic activity.

FOLLOW UP

A follow up of five to 30 years has been achieved in 57 cases. Seven of the early patients have been lost to follow up but the remainder have all been traced or have died from unrelated causes. Two patients have developed liver metastases nine and 16 years after lung resection. Among the nine patients treated by conservative bronchial resection with conservation of lung tissue there has been no recurrence of the tumour in the eight cases treated over five years ago or in the four cases treated over 10 years ago. An actuarially assessed life table analysis $^{33}$ of all 79 patients shows a $94 \% 10$ year, 


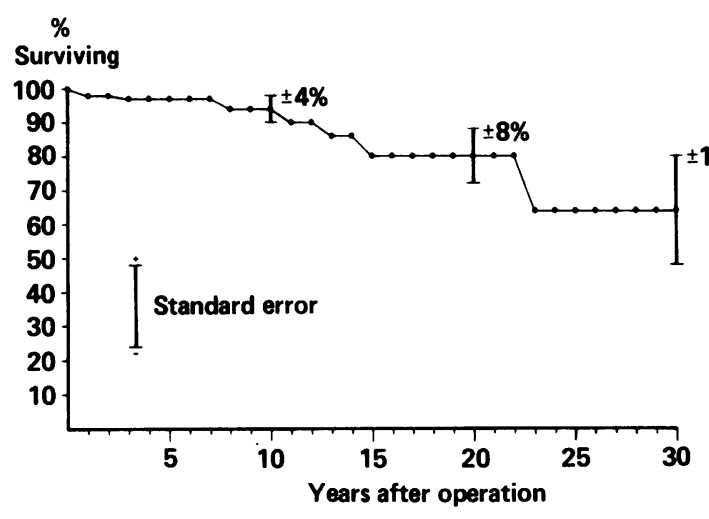

Fig 3 Actuarially assessed survival after removal of bronchial carcinoid (79 patients). One standard error of the mean gives an approximate $67 \%$ confidence interval.

$80 \% 15$ year, and $64 \% 25$ year survival rate without recurrence (fig 3 ).

The first patient who developed a recurrence had had a left lower lobectomy in 1962 at the age of 16 years and a completion pneumonectomy due to a local recurrence at the bronchial stump in 1970; then in 1979, at the age of 33 years, he was found to have extensive secondary deposits in the liver, confirmed to be bronchial carcinoid on liver biopsy. He has been treated by selective embolisation of the hepatic arteries with dura mater and gel foam and remains well and at work four and a half years after this procedure.

The second patient was aged 26 years and had a right lower lobectomy in $\mathbf{1 9 6 5}$ for a carcinoid in the apical segment of the right lower lobe. In 1981, 16 years later, he developed a respiratory infection and on bronchoscopy five very small polypoid lesions were seen at the origin of the left main bronchus. An excision biopsy of one of these lesions showed carcinoid. It is difficult to say whether this was indeed a recurrence or whether they were multiple second primary growths. He also had a very large liver and liver scan and ultrasound revealed multiple liver metastases, together with deposits in the spleen and retroperitoneal space. This was confirmed by liver biopsy. Arterial embolisation was not thought feasible in this case but he continues to remain suprisingly well two years later.

The histology of both these cases has been carefully reviewed and in both cases the appearances were of typical carcinoid, not the atypical variety. In neither case were glands found at operation to be affected by tumour, nor did carcinoid extend to the point of division of the bronchus.

\section{Discussion}

The sex, age distribution and symptoms of this series of patients with bronchial carcinoids closely resembles those reported previously, though the duration of symptoms was noticeably shorter in the more recent cases. It must be emphasised that early bronchoscopy is most important in any patient of any age who has repeated chest infection, haemoptysis, or a unilateral wheeze.

BIOPSY AND RISK OF HAEMORRHAGE It has repeatedly been stated in published reports, ${ }^{2791930}$ though with little statistical support, that biopsy in suspected carcinoid is contraindicated because of the risk of haemorrhage. This has not been our experience; appreciable haemorrhage after biopsy occurred in only two cases and this was easily controlled. Had it been more severe it would have been possible to control it with a Fogarty catheter, a double lumen endobronchial tube, or a bronchial blocker. Histological examination of the tumour before operation is most important if the correct operative procedure is to be undertaken. The increasing use of fibreoptic bronchoscopy, however, does cause a particular problem in patients who may have a carcinoid, for the control of haemorrhage at the time of fibreoptic bronchoscopy is virtually impossible. Moreover, the operative field is rapidly obscured by even a small amount of blood. The biopsy specimen taken at fibreoptic bronchoscopy is, of course, very small and perhaps haemorrhage is less likely. Our remarks about the safety of biopsy in bronchial carcinoid, which are in agreement with the conclusions of other recent papers, ${ }^{152627}$ refer only to rigid bronchoscopy and not fibreoptic bronchoscopy.

\section{SIMILARITY OF CARCINOID TO OAT CELL CARCINOMA}

The similarity of carcinoid to oat cell carcinoma on a small bronchial biopsy specimen has been noted by many authors, $10151924273134-8$ and this will become of increasing clinical importance with the more widespread use of fibreoptic bronchoscopy. Most bronchial carcinoids are readily distinguished from oat cell carcinoma by ordinary light microscopy, provided that the biopsy specimen is of adequate size. But this may not be the case with the small biopsy specimen obtained at fibreoptic bronchoscopy; and certainly one of our patients, a 35 year old doctor, was almost denied surgical cure as the minute biopsy specimen obtained at the initial fibreoptic bronchoscopy was thought to show oat cell carcinoma. There is an increasing tendency, incorrect in our view, to treat patients diagnosed as 
having oat cell carcinoma on bronchial biopsy only with radiotherapy or cytotoxic drugs (or both), even if the tumour is otherwise operable, as this is claimed to give the least unsatisfactory results. This produces a very real danger of totally inappropriate treatment, which is more likely to occur with the increasing use of fibreoptic bronchoscopy. There are many published reports of this confusion and a review of all long term survivors of oat cell carcinoma treated by radiotherapy or cytotoxic drug treatment might well reveal cases of unsuspected carcinoid tumour. On the other hand, some cases of carcinoid tumours that have been reported to have metastasised may well have been oat cell carcinoma.

It is not surprising that difficulties have been encountered in distinguishing carcinoid from oat cell carcinoma in view of recent work suggesting a similar cell of origin from the primitive endodermal canal. For many years isolated granular cells in the intestinal epithelium (Kultschitzky cells), which are argyrophilic, taking up silver in their granules, have been considered to be the cells of origin of intestinal carcinoid. In 1949 similar cells were also observed in the bronchial mucosa and electron microscopy showed identical granules in these cells, which were the main component of bronchial carcinoid. It was therefore considered that bronchial carcinoids arose from the Kultschitzky type of cell normally but scantily present in bronchial mucosa and also present in the intestinal mucosa. ${ }^{39}$

Oat cell carcinoma was subsequently shown by electron microscopy also to contain electron dense neurosecretory granules similar to those found in bronchial Kultschitzky cells and in the cells of bronchial carcinoid. ${ }^{40}$ These granules are identical in appearance, though they are more numerous in carcinoid. Furthermore, oat cell carcinoma and bronchial carcinoid may secrete a similar series of hormones, resulting in Cushing's syndrome, the carcinoid syndrome, or hyponatraemia with excessive secretion of antidiuretic hormone. They are both tumours of the APUD (amine precursor uptake and amino acid decarboxylation) cell series of hormone secreting cells, which are derived from the neural crest. On electron microscopy the cells have distinctive membrane bound granules in the cytoplasm. ${ }^{41}$

On the basis of these findings, bronchial carcinoid and oat cell carcinoma are thought to be both derived from the Kultschitzky type of cell normally found in bronchial mucosa, and to represent two extremes of malignant potential, the bronchial carcinoid being a locally spreading but basically benign tumour and the oat cell carcinoma being an anaplastic and highly malignant form of tumour. This must not, however, be interpreted as implying that a tumour that commences as a bronchial carcinoid may undergo a metamorphosis to an oat cell carcinoma, for which there is no clinicopathological evidence.

The features which differentiate a carcinoid from an oat cell carcinoma have been described by Fisher et $a l,{ }^{42}$ but in some cases they are thought to be capable of differentiation only by electron microscopy. ${ }^{43}$ If this is confirmed it poses a very real problem for the thoracic pathologist in a district hospital, where electron microscopy is less easily available. Perhaps its use will be required only in selected cases. ${ }^{44}$ The relationship between oat cell carcinoma and carcinoid has been discussed recently in detail by Shimosoto et al..$^{45}$

\section{EXTENT OF RESECTION}

There is still much controversy concerning the true nature of bronchial carcinoid and its degree of malignancy, ranging from the experience of the Memorial Cancer Center in New York ${ }^{18}$ that it is a rapidly growing tumour with a discouraging five year survival rate to the Mayo Clinic experience ${ }^{2}$ of a relatively benign tumour with an $87 \% 10$ year survival rate. There is so much difference of opinion in published reports about the malignancy of this tumour that one sometimes wonders whether the same tumour is being discussed. This can be due only to a difference in interpretation and classification of the histological appearances. Carcinoid tumours of the lung are not uncommonly misdiagnosed as oat cell carcinoma, the correct diagnosis being made only retrospectively by histochemical and electron microscopy techniques. Likewise a highly differentiated bronchial carcinoma may be difficult to differentiate from a carcinoid. There are many reports of these errors being made. Another reason for the conflicting views is that in many reports carcinoid has not been separated from the much less common adenoid cystic carcinoma (cylindroma), a tumour which is very much more malignant. The main objection to classification of carcinoid tumours as malignant is the clinical behaviour. It is often associated with long survival even in the absence of effective treatment, ${ }^{24} 46$ and even if there is carcinoid at the line of bronchial resection. ${ }^{26}$

If the lymph nodes are affected by tumour then naturally a more radical operation should be undertaken, but often the lymph node enlargement is due to pulmonary infection and not to tumour. The question of lymph node disease should be assessed by frozen section at the time of operation and not in retrospect in the laboratory. In only one of the cases reported here were glands affected by tumour.

There has been considerable discussion recently about atypical carcinoid tumours of the lung, which 
are thought to have a greater malignant potential and are more likely to metastasise locally or outside the chest. ${ }^{47}$ This discussion has centred on the histological appearances of the tumour and not on the presence or absence of affected glands. The carcinoid is described as atypical if there is increased mitotic activity, if the nuclei are irregular and the nucleoli prominent, or if there are areas of increased cellularity or areas of tissue necrosis. Atypical carcinoid is not always aggressive and is not necessarily associated with diseased glands. Moreover, glandular disease does not occur only in atypical carcinoid. There was one case of atypical carcinoid in this series. It has also been said ${ }^{24}$ that the degree of malignancy should be assessed not only on the histological appearance but also according to whether the tumour has penetrated the bronchial mucosa at the time of operation and whether the tumour is intrabronchial or intrapulmonary, these two factors being of even greater importance than the histological appearances and the possibility that the carcinoid is atypical. The whole problem is very complex and no firm conclusion about the prognosis of these atypical carcinoids can yet be given.

In view of these conflicting views how extensive should the resection for bronchial carcinoid be? This question constantly recurs in publications about this condition, and although earlier reports emphasised the innocent nature of these tumours some more recent articles have emphasised their malignant potential and have advised against conservative surgery, recommending that all cases should be treated by lobectomy or pneumonectomy. Our experience is that a carcinoid tumour of the lung should be considered to be a tumour of only slight malignant potential, which may be treated conservatively by resection of the tumour by bronchotomy or sleeve resection of the bronchus. In practice, however, lung resection is frequently required, and in this series infective changes distal to the tumour or extension of the tumour into the lung parenchyma (so called iceberg tumour) made lung resection necessary in $88 \%$ of cases. This conservative approach has been vindicated by the satisfactory outcome in the nine cases so treated, in all of which a lobectomy or pneumonectomy would otherwise have been required. These are also the views expressed during the last four years by the Mayo Clinic $^{48}$ and by Todd et al from Toronto. ${ }^{26}$ The potential malignancy of carcinoid is likely to have been overstated by some authors in the past.

The use of a Gebauer skin graft, described in more detail elsewhere, ${ }^{49}$ enabled conservation of lung tissue in four cases, in three of which an upper lobectomy and in one of which a middle and lower lobectomy would otherwise have been required. It is a largely forgotten technique, originally described for the treatment of tuberculous strictures of the main bronchus; ${ }^{50}$ but is less likely to cause late postoperative problems than the use of inert materials such as tantalum gauze wrapped in fascia ${ }^{19}$ or teflon. $^{24}$

\section{LATE METASTASES}

The late development of metastases in two patients and their clinical state is of interest. The liver secondaries must presumably have been present for nine and 16 years after resection of the pulmonary tumour; and despite the extent of the recurrence the patients were both able to remain at work, one without having had any treatment. The multiple, minute, polypoid lesions at the origin of the opposite main bronchus in the second patient were unexpected. They were in an unlikely site for secondary deposits and were presumably new primary growths. It is known that peripheral carcinoid tumours may be multicentric and therefore multiple ${ }^{1251}$ and this was perhaps the case in this patient, although we have not been able to find in published reports any other cases of multiple bronchial polypoid lesions.

We wish to thank Professor GL Grunkemeier for the production of the life table and the actuarially assessed survival curve. We are also indebted to $\mathrm{Mr}$ A de Bono, under whose care was the one patient with atypical carcinoid.

\section{Addendum}

Since the submission of this paper one further patient, aged 56 years, has developed hepatic metastases three years after lower lobectomy. This was confirmed by biopsy and was associated with a classical carcinoid syndrome and a raised blood serotonin concentration. Another patient, aged 65 years, diagnosed as having carcinoid tumour at fibreoptic bronchoscopy, was found at thoracotomy to have an oat cell carcinoma. Two further patients, women aged 47 and 49 years, with bronchial carcinoid tumour have been treated by right lower lobectomy.

\section{References}

' Cooper DKC, Belcher JR. Conservative surgery for bronchial adenomata. Thorax 1976;31:44-8.

${ }^{2}$ Okike N, Bernatz P, Woolner LB. Carcinoid tumours of the lung. Ann Thorac Surg 1976;22:270-5.

${ }^{3}$ Aberg T, Blöndal T, Nõu E, Malmaeus J. The choice of operation for bronchial carcinoids. Ann Thorac Surg 1981;32:19-22.

${ }^{4}$ Blöndal T, Grimelious L, Nõu E, et al. Argyrophil carcinoid tumours of the lung: incidence, clinical study, and follow-up of 46 patients. Chest 1980;78:840-4.

${ }^{5}$ Baldwin JN, Guines ÖF. Bronchial adenomas. Surg 
Gynecol Obstet 1967;124:813-8.

${ }^{6}$ Batson JF, Gale JW, Hickey RC. Bronchial adenomas: a clinical resumé. Arch Surg 1966;92:623-30.

' Bower G. Bronchial adenoma. Am Rev Respir Dis 1965;92:558-63.

${ }^{8}$ Boyd AD, Spencer FC, Lind A. Why has bronchial resection and anastomosis been reported infrequently for the treatment of bronchial adenoma? J Thorac Cardiovasc Surg 1970;59:359-65.

${ }^{9}$ Burcharth F, Axelsson C. Bronchial adenomas. Thorax 1972; 27:442-9.

${ }^{10}$ Carlens E, Wiklund T, Bergstrand A. Bronchial adenoma: a report of 70 cases and a critical analysis of the literature. Acta Chir Scand 1954;185, suppl: 7-55.

"Giustra PE, Stassa G. The multiple presentations of bronchial adenomas. Radiology 1969;93:1013-9.

${ }^{12}$ Heimburger I, Kilman J, Battersby J. Peripheral bronchial adenomas. J Thorac Cardiovasc Surg 1966;52:542-9.

${ }^{13}$ Jensik RJ, Faber LP, Brown CM, Kittle F. Bronchoplastic and conservative resectional procedures for bronchial adenoma. J Thorac Cardiovasc Surg 1974;68:556-65.

${ }^{14}$ Kennedy A. The diagnosis of pulmonary carcinoid tumours. Br J Dis Chest 1979;73:71-80.

is Lawson RM, Ramanathan L, Hurley G, et al. Bronchial adenoma: review of an 18-year experience at the Brompton Hospital. Thorax 1976;31:245-52.

${ }^{16}$ Meffert WG, Lindskog GE. Bronchial adenoma. $J$ Thorac Cardiovasc Surg 1970;59:588-602.

${ }^{17}$ Miller RE, Hopeman AR. Bronchial adenoma. Ann Thorac Surg 1975; 19:378-85.

${ }^{18}$ O' Grady WP, McDivitt RW, Holman CW, Moore SW. Bronchial adenomas. Arch Surg 1970;101:558-61.

${ }^{19}$ Overholt RH, Bouges JA, Morse DP. Bronchial adenoma: a study of 60 patients with resections. $A m$ Rev Tuberc Pulm Dis 1957; 75:865-84.

${ }^{20}$ Rabin CB, Neuhof $H$. Adenoma of the bronchus. $J$ Thorac Surg 1949;18:149-63.

${ }^{21}$ Roenspies U, Fenniger EP, Otto R, Senning A. Bronchialcarzinoide. Thoraxchirurgie 1976;24:154-63.

${ }^{22}$ Salyer D, Salyer WR, Eggleston JC. Bronchial carcinoid tumours. Cancer 1975;36:1522-37.

${ }^{23}$ Schmid de Gruneck JM, Naef AP, Bauman RP. Adenomas bronchiques. Schweiz Med Wochenschr 1977; 107:259-66.

${ }^{24}$ Smith RA. Bronchial carcinoid tumours. Thorax 1969;24:43-50.

${ }^{25}$ Soutter L, Sniffen RC, Robbins LL. A clinical survey of adenomas of the trachea and bronchus in a general hospital. J Thorac Surg 1954;28:412-30.

${ }^{26}$ Todd JR, Cooper JD, Weissberg D, Delarue NC, Pearson FG. Bronchial carcinoid tumours -20 years' experience. J Thorac Cardiovasc Surg 1980; 79:532-6.

${ }^{27}$ Tolis GA, Fry WA, Head L, Shields TW. Bronchial adenomas. Surg Gynecol Obstet 1972;134:605-10.

${ }^{28}$ Turnbull AD, Huvos AG, Goodner JT, Beattie EJ. The malignant potential of bronchial adenoma. Ann Thorac Surg 1972;14:453-64.

${ }^{29}$ Weiss L, Ingram M. Adenomatoid bronchial tumours. Cancer 1961;14:161-78.

${ }^{30}$ Wilkins EW Jr, Barling RC, Soutter L, Sniffen RC. A continuing clinical survey of adenomas of the trachea and bronchus in a general hospital. J Thorac Cardiovasc Surg 1963;46:279-91.
${ }^{31}$ Zellos S. Bronchial adenoma. Thorax 1962;17:61-8.

${ }^{32}$ Bronchial adenomas. Br Med J 1981; 282:252.

${ }^{33}$ Anderson RP, Bonchek LL, Grunkemeier GL, Lambert LE, Starr A. The analysis and presentation of surgical results by actuarial methods. J Surg Res 1974; 16:224-30.

${ }^{34}$ Jackson CL, Konzelmann FW. So called adenoma of bronchus. Ann Otol Rhinol Laryngol 1941;50:126469.

${ }^{35}$ Goodner JT, Berg JW, Watson WL. The non-benign nature of bronchial carcinoids and cylindromas. Cancer NY 1961;14:539-46.

${ }^{36}$ Markel SF, Abell MR, Haight C, French AJ. Neoplasms of bronchus commonly designated as adenomas. Cancer NY 1964;17:590-608.

${ }^{37}$ Paulson DL, Reisch JS. Long term survival after resection for bronchogenic carcinoma. Ann Surg 1976; 184:324-31.

${ }^{38}$ Kennedy A. The diagnosis of pulmonary carcinoid tumours. Br J Dis Chest 1979;73:71-80.

${ }^{39}$ Froehlich F. Die 'Helle Zelle' der bronchialschleimhaut und ihre beziehungen zum problem der chemoreceptoren. Frankf Z Pathol 1949;60:517-57.

${ }^{40}$ Bensch KG, Corrin B, Pariente R, Spencer H. Oat cell carcinoma of the lung: its origin and relationship to bronchial carcinoid. Cancer 1968;22:1163-72.

${ }^{41}$ Pearse AGE. The cytochemistry and ultrastructure of polypeptide hormone-producing cells of the APUD series and the embryologic, physiologic and pathologic implications of the concept. J Histochem Cytochem 1969;17:303-13.

${ }^{42}$ Fisher ER, Palekar A, Paulson JD. Comparative histopathologic, histochemical, electron microscopic and tissue culture studies of bronchial carcinoids and oat cell carcinomas of lung. Am J Clin Pathol 1978;69:165-72.

${ }^{43}$ McDowell EM, Sorokin SP, Hoyt RF, Trump BF. Atypical neurosecretory cell tumours of the lung - an unrecognised entity. Lab Invest 1979;40:272.

${ }^{44}$ Heard BE, Dewar A, Firmin RK, Lennox S. One very rare and one new tracheal tumour found by electron microscopy: glomus tumour and acinic cell tumour resembling carcinoid tumours by light microscopy. Thorax 1982;37:97-103.

${ }^{45}$ Shimosoto Y, Melamed MR, Nettesheim P. Morphogenesis of lung cancer. Vol 2. Boca Raton, Florida: CRC Press, 1982:15-43.

${ }^{46}$ Borggreve JR. A bronchial adenoma of 33 years standing [in Dutch with English summary]. Ned T Geneesk 1966; 110: 1532-5.

${ }^{47}$ Arrigoni MG, Woolner LB, Bernatz PE. Atypical carcinoid tumours of the lung. $J$ Thorac Cardiovasc Surg 1972;64:413-21.

${ }^{48}$ Okike N, Bernatz PE, Payne WS, Woolner LB, Leonard $\mathrm{PF}$. Bronchoplastic procedures in the treatment of carcinoid tumours of the tracheobronchial tree. $J$ Thorac Cardiovasc Surg 1978;76:281-91.

${ }^{49}$ Hurt R. Benign tumours of the bronchus and trachea, 1951-81. Ann R Coll Surg Engl 1984;66:22-6.

${ }^{\text {so }}$ Gebauer $P$. Reconstructive surgery of the trachea and bronchi: late results with dermal grafts. J Thorac Surg 1951;22:568-84.

${ }^{51}$ Felton WL, Liebow AA, Lindskog GE. Peripheral and multiple bronchial adenomas. Cancer 1953;6:555-67. 